А. Л. БАРДИН, В. В. СТОМИН

\title{
ИСКУССТВЕННЫЙ ИНТЕЛЛЕКТ
}

В УПРАВЛЕНИИ ГОРОДОМ:

БАРЬЕРЫ И ПЕРСПЕКТИВЫ ВНЕДРЕНИЯ

В статье рассматриваются актуальные проблемные аспекты, связанные с внедрением автоматизированных систем, построенных на технологии искусственного интеллекта (ИИ), в процессы государственного управления, прежде всего на городском (муниципальном) уровне. Показано, что на данный прочесс влияют три ключевые группы факторов: рыночные (вопросы развития рынка ИИ-решений и его взаимодействия с государством); этическо-технологические (вопросы транспарентности и подотчетности алгоритмов ИИ, доверия к автоматизированным системам, обеспечения интероперабельности ИИ-систем и данных); нормативные (трансформащия существующих и принятие новых нормативно-правовых актов, регулирующих сферу ИИ). Все три группы факторов тесно связаны между собой, и для успешного внедрения ИИ-решений необходимо параллельное решение задач в каждой из этих групп. Авторы выделяют наиболее значимые барьеры на пути внедрения ИИ-решений в государственном управлении и обозначают инструменты преодоления каждого из барьеров.

Ключевые слова: искусственный интеллект, этика, ицирровизация, автоматизированные системы, государственное управление, государственные услуги, городское управление, органь исполнительной власти, IT-компании.

\section{Введение}

Решения на основе комплекса технологий, обозначаемых как искусственный интеллект (ИИ $)^{1}$, в 2020-2021 гг. прочно заняли ли-

${ }^{1}$ Искусственный интеллект - способность технической системы имитировать когнитивные функции человека (включая самообучение и поиск решений без заранее заданного алгоритма) и получать при выполнении конкретных практически значимых задач обработки данных результаты, сопоставимые как минимум с результатами интеллектуальной деятельности человека. См. ГОСТ Р 59276-2020, ст. 3.6. 
дирующие позиции в рейтингах наиболее перспективных технологий, составляемых мировыми аналитическими агентствами. ИИ-решения имеют огромный потенциал - по некоторым оценкам, экономический эффект от их внедрения в ближайшие десять лет может составить до триллиона долларов (Blumauer 2020) - и уже оказывают заметное воздействие на развитие различных отраслей экономики. В 2020 г. объем инвестиций в разработки на основе технологий ИИ вырос на рекордные $40 \%$ по сравнению с предыдущим годом и составил 67,9 млрд долларов (Measuring... 2021: 93), а объем глобального ИИ-рынка - более 281,4 млрд долларов с перспективой роста в 2021 г. до 16,4 \% (IDC... 2021).

Массовая цифровизация государственного управления готовит и эту в целом консервативную сферу к ИИ-трансформации. Этому способствует также общий тренд на демократизацию ИИ - аналитики Gartner констатируют, что ИИ перестает быть уделом экспертов и охватывает все более широкую аудиторию (2 Megatrends... 2020).

Решения на базе ИИ могут способствовать качественному совершенствованию целого ряда процессов в сфере государственного управления. Так, эксперты Департамента по искусственному интеллекту правительства Великобритании полагают наиболее перспективными следующие направления применения ИИ-решений (A Guide... 2020: 6):

- предоставление более корректной информации и формирование прогнозов;

- продвижение в решении социальных проблем;

- создание симуляционных моделей сложных систем, которые позволят оценить возможный эффект от принятия тех или иных политических решений (тем самым продвинувшись в решении главной проблемы общественных наук - отсутствующей возможности проведения реального, не мыслительного, эксперимента. Прим. авт.);

- повышение качества государственных услуг;

- автоматизация рутинных действий, требующих значительных временных затрат.

Насколько удастся реализовать прогнозируемый потенциал ИИ в этой сфере, во многом зависит от преодоления немалого числа 
барьеров, стоящих на пути внедрения ИИ-решений. Настоящая статья сфокусирована на главных из таких барьеров и перспективных практиках их преодоления. Авторы предпринимают попытку сформулировать набор универсальных инструментов (policy tools), актуальных для городов, которые ставят перед собой задачи внедрения ИИ в сферу управления, а также развития города как «питательной среды» для распространения технологий ИИ.

Методология исследования включает в себя метод анализа кейсов (case study), компаративистский метод (comparative study), а также метод экспертных интервью. При подготовке текста проведено 10 глубинных интервью на условиях анонимности, в том числе пять интервью с представителями органов исполнительной власти федерального уровня и города Москвы (респонденты 1-5), а также пять интервью с представителями компаний, входящих в ведущие российские IT-ассоциации, - Ассоциации предприятий компьютерных и информационных технологий (АПКИТ) и Некоммерческого партнерства разработчиков программного обеспечения РУССОФТ (НП РУССОФТ) (респонденты 6-10).

$$
* * *
$$

Внедрение автоматизированных систем ${ }^{2}$ в городское управление демонстрирует ярко выраженную положительную динамику. Перечислим наиболее важные причины такого развития событий. Во-первых, это экспоненциальный рост количества данных, генерируемых жителями города, которые органам исполнительной власти (ОИВам) необходимо обрабатывать и анализировать для предоставления качественных услуг и сервисов. При этом способность человека ориентироваться в таком объеме данных имеет очевидные ограничения.

Во-вторых, требования к качеству государственных услуг постоянно растут, а в условиях постоянной конкуренции городов за человеческий капитал и финансовые потоки высокое качество сервисов приобретает стратегическое значение. Однако объем ресурсов, находящихся в распоряжении городских властей, растет значи-

\footnotetext{
${ }^{2}$ Автоматизированная система - система, состоящая из персонала и комплекса средств автоматизации деятельности и использующая информационные технологии выполнения установленных функций. См. ГОСТ 34003-90, ст. 1.1.
} 
тельно медленнее этих требований, а в кризисных условиях, таких как пандемия COVID-19, заметно сокращается. Вкупе с ростом гражданского контроля за государственными расходами с иелью ux оптимизации эти факторы формируют спрос на решения, позволяющие предоставлять качественные сервисы при минимуме затрат и оптимизировать городской бюджет.

B-третьих, тренд на цифровизацию государственного управления сформировал конкурентную среду, в которой ОИВы, избегающие внедрения автоматизации либо запаздывающие с принятием и реализацией стратегий цифровой трансформации, подпадают под риск сокращения бюджетов по сравнению с ОИВами, проводящими цифровизацию. Таким образом, внедрение ИИ-решений становится фактором конкурентоспособности государственных учреждений на «рынке государственного бюджетирования».

\section{Российский рынок ИИ-решений}

Неотъемлемой частью проблематики внедрения ИИ-решений в государственное управление - которое является стратегически значимой сферой, где применение зарубежных технологий возможно либо эпизодически, либо невозможно в принципе - является вопрос развития отечественного рынка ИИ-решений. Авторы, исследующие эту проблематику, в целом солидарны в том, что фундаментальными факторами, сдерживающими развитие рынка ИИ в России, являются слабость экономики, правовые барьеры и низкий уровень доверия к государству (см., например: Косалс, Ячник 2020: 12-13). Респонденты из ІТ-ассоциаций (АПКИТ, РУССОФТ) выделили следующие пять барьеров.

1. Отсутствие стабильного рынка сбыта и финансовых гарантий эффективности. Несмотря на «хайп» вокруг технологий ИИ, бизнес пока не видит достаточных гарантий, дающих основания для существенных инвестиций в эту сферу, и прежде всего гарантированного рынка сбыта в лице государства. Кроме того, как показало исследование TAdviser и «Ростелеком», оценить реальный эффект от внедрения искусственного интеллекта весьма трудно. Хотя уже более $85 \%$ крупных российских компаний используют (внедряют или тестируют) технологии ИИ для оптимизации внутренних бизнес-процессов, только для $18 \%$ из них финансовые 
службы подтвердили экономический эффект от внедрения ИИ (Эффекты... 2020: 3).

2. Отсутствие четких правил игры. Российский регуляторный ландшафт в сфере ИИ постоянно совершенствуется, однако попрежнему весьма тернист. Многие вопросы применения ИИ-технологий остаются вне правового поля, по другим НПА еще только разрабатываются.

3. Финансовые трудности. Согласно поправкам, внесенным в Налоговый кодекс РФ и вступившим в силу с 1 января 2021 г., для российских IT-компаний введен очередной пакет льгот, в том числе пониженные тарифы страховых взносов в совокупном размеpe 7,6 \%. Однако, по словам респондентов, если финансовая нагрузка на компании, профилем которых является разработка ПО, уменьшилась, то нагрузка на средние и крупные компании, напротив, возросла, в связи с чем им пришлось столкнуться с целым рядом сложностей организационно-финансового характера.

4. Международные санкции и жесткий механизм валютного контроля. Хотя представители IT-компаний отмечают, что валютный контроль в последнее время был упрощен, компании попрежнему испытывают сложности при экспорте IT-решений. При выводе выручки из-за рубежа необходимо предоставлять огромное количество документов, на различных этапах работа на экспорт сопряжена с большим количеством бюрократических процедур.

5. Политика государства в сфере IT-инсорсинга. Респонденты отметили, что ставшая широко распространенной в России практика, когда государственные компании создают собственные IT-компании либо приобретают существующие, приводит к двум проблемам. Во-первых, такими структурами часто тратятся огромные средства на разработку решений, уже имеющихся на рынке. Во-вторых, эти государственные средства не приходят на рынок, что ведет к его «опустыниванию».

В то же время респонденты положительно оценили такие меры поддержки российских IT-компаний, как снижение налога на прибыль с $20 \%$ до $4 \%$ для IT-компаний в рамках общей системы налогообложения, освобождение от НДС при реализации ПО, а также субсидии на развитие проектов с использованием технологий ИИ и создание открытых ИИ-библиотек. 


\section{Государственный сектор}

Внедрение любых инноваций сопряжено с целым рядом барьеров и опасений. Сфера городского управления имеет свою специфику, однако из опыта внедрения ИИ в различных отраслях экономики показательными являются результаты опроса работников банковской сферы (руководителей IT- и инновационных подразделений банков, поставщиков банковских систем и экспертов в области ИИ), который был проведен М. Р. Лотош, В. В. Платоновым и П. П. Ткалич.

По мнению опрошенных, главными барьерами, препятствующими внедрению ИИ, выступили:

- недостаточная компетентность сотрудников;

- сложность интерпретации результатов;

- отсутствие необходимой инфраструктуры;

- разрозненность данных различных информационных систем;

- высокая стоимость ИИ-решений.

Кроме того, в числе значимых барьеров респонденты выделили трудности юридического характера (валидация модели регулятором), проблемы безопасности (несоответствие ИИ-решений стандартам и политике безопасности банка), страх безработицы и, наконец, недоверие к решениям, принятым ИИ (Лотош и др. 2021).

Указанные факторы актуальны и для сферы городского управления: это подтвердили интервью, проведенные авторами с представителями ОИВов, в которых респонденты приводили аналогичную аргументацию. Рассмотрим основные группы вопросов, озвученные в ходе интервью.

Kaдpbl. По данным АПКИТ, на 2020 г. потребность России в высококвалифицированных IT-кадрах составила 222 тыс. человек в год, в то время как число соответствующих выпускников вузов - 50 тыс. человек в год. По профилю ИИ в целом по России ежегодно выпускается 18 тыс. студентов, что ниже требуемого уровня в 3 раза. В сфере государственного и муниципального управления кадровый голод отражается в нехватке компетентных специалистов по цифровой трансформации. «Как правило, на местах цифровую трансформацию понимают как простой перевод документов из бумаги 
в ичифру. В результате концепции, которые принимаются на местах, часто далеки от концепций верхнего уровня» (респондент 1).

Помимо системных мер по наращиванию мощностей системы образования и укреплению связки «вузы - корпорации» (см. табл. 1), респонденты в числе актуальных для ОИВов назвали следующие практики:

- внедрение концепции непрерывного обучения и программ повышения квалификации;

- проведение «глубоких погружений» (deep dive) и воркшопов (workshop) по ИИ-решениям;

- введение должности уполномоченного по ИИ, обладающего профильными компетенциями.

Таблииа 1

ИИ в городском управлении: кадры

\begin{tabular}{|c|c|}
\hline Бар & Инструменты преодоления \\
\hline $\begin{array}{l}\text { 1. Недостаточный объем подго- } \\
\text { товки ІТ-кадров, нехватка спе- } \\
\text { циалистов по ИИ. } \\
\text { 2. Низкий уровень вовлеченно- } \\
\text { сти студентов старших курсов } \\
\text { и выпускников вузов в ИИ- } \\
\text { экосистему. } \\
\text { 3. Малое число механизмов } \\
\text { формирования новых команд } \\
\text { для разработки ИИ-решений. } \\
\text { 4. Низкий уровень квалифика- } \\
\text { ции кадров по цифровой транс- } \\
\text { формации (или их отсутствие) } \\
\text { в городских структурах - ос- } \\
\text { новных потенциальных заказ- } \\
\text { чиках ИИ-решений }\end{array}$ & $\begin{array}{l}\text { 1. Программа повышения квалификации } \\
\text { сотрудников ОИВов, ответственных за } \\
\text { цифровую трансформацию. } \\
\text { 2. Программа стажировок молодых спе- } \\
\text { циалистов (студентов старших курсов) } \\
\text { в государственном и частном секторах } \\
\text { на проектах, включающих ИИ-решения, } \\
\text { софинансируемая из федерального или } \\
\text { городского бюджета. } \\
\text { 3. Распространение практики «Стартап } \\
\text { как диплом» в вузах города с целью } \\
\text { привлечения талантов в экосистему тех- } \\
\text { нологического предпринимательства. } \\
\text { 4. Организация совместных с корпора- } \\
\text { циями образовательных курсов в сфере } \\
\text { ИИ на различных уровнях образования. } \\
\text { 5. Создание базовых кафедр в области } \\
\text { ИИ в вузах совместно с ведущими кор- } \\
\text { порациями. } \\
6 . \text { Увеличение количества мест в вузах } \\
\text { по ІТ-специальностям }\end{array}$ \\
\hline
\end{tabular}


Нормативное регулирование. Необходимым условием для полноценного развития и применения ИИ выступает всеохватное правовое регулирование этой сферы. Большинство респондентов выразили озабоченность следующими факторами. Во-первых, это проблема несовместимости ряда положений законодательства о защите данных с технологиями ИИ, прежде всего в части обработки больших данных. Во-вторых, отсутствие закрепленного порядка разбора ситуаций и определения ответственных в случаях принятия ИИ ошибочного решения / сбоя в программе. В-третьих, проблема закупки ИИ-решений: у государственных заказчиков, как правило, отсутствует понимание того, как проводить конкурс на ИИ-решения, в частности, подготавливать технические задания, в том числе по 44-Ф3 и 223-Ф3, а в нормативных документах не зафиксированы требования к конкретным технологиям и ПО ${ }^{3}$.

Респонденты отметили, что часть из этих проблем может снять введение «регуляторных песочниц», таких как Экспериментальный правовой режим в сфере искусственного интеллекта (ЭПР ИИ), введенный с 1 июля 2020 г. в Москве на основании Федерального закона от 24.04.2020 № 123-Ф3 об эксперименте по ИИ в городе Москве.

В ходе этого эксперимента планируется:

- предоставлять участникам доступ к обезличенным городским данным для обучения ИИ;

- идентифицировать барьеры, препятствующие внедрению ИИ, и снимать их при помощи московских и федеральных нормативноправовых актов (см. табл. 2);

- создать инфраструктуру для совместной разработки решений;

- обеспечить стабильный спрос на ИИ-решения через государственных и частных потребителей.

Одна из приоритетных задач, которую позволит решить ЭПР ИИ, - возможность для компаний-участников обрабатывать обезличенные персональные данные граждан из сфер общественного

3 Для практического преодоления проблемы закупки ИИ-решений государственными структурами может быть полезен опыт Великобритании, где разработан официальный документ «Рекомендации по закупке ИИ-решений» (Guidelines... 2020: 26), которым госзаказчики могут руководствоваться в своей работе. 
транспорта, здравоохранения, распознавания лиц, что повысит качество новых ИИ-решений и ускорит обучаемость систем. Также ЭПР ИИ упростит механизм взаимодействия рынка и государственного сектора, позволит компаниям предлагать Правительству Москвы продукты для последующей закупки в рамках государственного заказа или организации проекта государственно-частного партнерства.

Мониторинг эксперимента осуществляет Координационный совет, в который входят представители Правительства Москвы, Правительства РФ, Администрации президента, Совета Федерации и ПАО «Сбербанк».

Таблица 2

ИИ в городском управлении: нормативные аспекты

\begin{tabular}{|c|c|}
\hline Барьеры & Инструменты преодоления \\
\hline $\begin{array}{l}\text { 1. Недостаточный уровень } \\
\text { обеспеченности сферы } \\
\text { ИИ нормативно-техническим } \\
\text { регулированием. } \\
2 . \text { Наличие административных } \\
\text { барьеров на пути к внедрению } \\
\text { ИИ в различных сферах эконо- } \\
\text { мики, сложность администра- } \\
\text { тивно-правового и нормативно- } \\
\text { технического порядка тестиро- } \\
\text { вания и внедрения разработок } \\
\text { в сфере ИИ. } \\
\text { 3. Несовместимость отдельных } \\
\text { положений законодательства } \\
\text { о защите данных с технология- } \\
\text { ми ИИ. } \\
4 . \text { Проблема закупки ИИ-реше- } \\
\text { ний государственными заказ- } \\
\text { чиками }\end{array}$ & $\begin{array}{l}\text { 1. Закрепление в НПА порядка разбора } \\
\text { ситуаций и определения ответственных } \\
\text { в случаях принятия ИИ ошибочного } \\
\text { решения / сбоя в программе. } \\
\text { 2. Принятие НПА, снимающих часть } \\
\text { ограничений, накладываемых Законом } \\
\text { о защите персональных данных. } \\
\text { 3. Разработка единых стандартов требо- } \\
\text { ваний для ИИ-решений. } \\
\text { 4. Разработка рекомендаций по закупке } \\
\text { ИИ-решений, типовых ТЗ, применение } \\
\text { «коробочных решений» при проведении } \\
\text { ОИВами конкурсов на ИИ-решения. } \\
\text { 5. Внедрение регуляторных «правовых } \\
\text { песочниц» и экспериментальных право- } \\
\text { вых режимов }\end{array}$ \\
\hline
\end{tabular}

Данные. Эту сферу абсолютное большинство респондентов назвали в числе приоритетных. Современный город насыщен огромным количеством данных - это информация о трафике и парковках, спутниковые снимки, сообщения граждан, происшествия, оценки учащихся и потребление коммунальных ресурсов. Объем 
данных растет гигантскими темпами: 90 \% данных, которыми оперируют города, появились лишь за последние 2 года.

Решения для анализа больших данных активно применяются в управлении городами ${ }^{4}:$ так, реализованные в Москве решения позволяют экономить бюджетные средства и прогнозировать потребности жителей, например, планировать строительство новых школ и больниц, подстраивать расписание и маршруты общественного транспорта под запросы горожан, повышать безопасность на дорогах ${ }^{5}$.

Важным преимуществом ИИ является то, что основанные на этой технологии решения позволяют выйти на новый уровень предоставления сервисов, перейдя от оказания услуг «по факту» к предиктивным и кастомизированным услугам, которые предугадывают потребности жителя и учитывают историю его обращений к государству. Пример - внедренный в Москве сервис «Таргетированные персональные коммуникации», который используется для организации тематических и событийных коммуникационных кампаний в адрес жителей Москвы в соответствии с их реакциями и предпочтениями, в том числе по каналу коммуникации, а также

\footnotetext{
${ }^{4}$ Один из наиболее ярких примеров - кейс Нью-Йорка. Департамент строительства Нью-Йорка длительное время не мог решить проблему: как выстроить приоритеты в мониторинге зданий на предмет противопожарной безопасности. Осмотр всех зданий подряд занял бы слишком много времени, так как число инспекторов, выезжающих на объекты, ограничено. Решение удалось найти с помощью агрегирования данных, полученных от инспекторов. Предикативная ИИ-модель на их базе позволила определить, какие именно характеристики состояния здания наиболее значимы с точки зрения пожарной безопасности. В соответствии с этим каждому зданию в городе был присвоен индекс риска. Если до создания модели только 13 \% выездов инспекторов выявляли ситуации высокого риска, то после ее запуска этот показатель вырос до 70 \%. Это позволило существенно снизить число пожаров и пострадавших от них (см.: Making... 2017).

${ }^{5}$ Пример такого решения - Интеллектуальная транспортная система города Москвы (ИТС), запущенная в 2011 г. На современном этапе развития ИТС оснащена постоянно обучающимся ИИ, который осуществляет мониторинг ситуации на дорогах. ИТС охватывает всю территорию столицы и объединяет несколько десятков тысяч транспортных объектов, в том числе 40 тыс. светофоров, 3700 детекторов транспорта, более 2700 камер телеобзора, 48 метеостанций, более 170 дорожных табло отображения информации. Благодаря внедрению ИТС и комплексу сопутствующих мер средняя скорость движения личного транспорта в Москве увеличилась на $16 \%$, а количество ДТП снизилось на 59 \% по сравнению c 2010 г.
} 
формирования таргетированной новостной ленты и информации о государственных услугах на сайте mos.ru.

В то же время работа с данными сопряжена со значительными рисками, главные из которых - утечка личных данных в результате человеческого фактора или кибератак. «Актуальность проблемы крайне высока - мы видим, что почти 75 \% кибератак начелены на системы безопасности госсектора, а глобальная статистика утечки данных по неосторожности либо некомпетентности сотрудников весьма неутешительна. Прежде чем применять новые технологии, необходимо обеспечить безопасность данных, с которыми она будет иметь дело» (респондент 2).

Проблема несет высокие репутационные и управленческие риски для городских властей и ведет к росту конфликтов и углублению размежеваний в обществе - прежде всего на почве протеста против сбора биометрических данных граждан, развертывания систем видеонаблюдения и основанных на них аналитических инструментов. Обеспечение безопасности данных - обязательное условие для внедрения ИИ-решений, солидарны респонденты.

Проведенные интервью выявили целый ряд других проблемных аспектов, связанных с работой с данными. Приоритетным респонденты назвали комплекс проблем, порожденных отсутствием единого стандарта обработки, формата представления и обновления данных, а также единого протокола обмена данными. Другими словами - отсутствием единой информационной среды в сфере государственного управления, в которой был бы решен вопрос интероперабельности государственных информационных систем (ГИС) и информационных систем специальной деятельности различных ведомств.

Еще одна важная проблема, по мнению ряда респондентов представителей IT-компаний, - часто некорректное понимание государственными чиновниками вопроса работы с наборами данных. Речь идет о реализации поручения Президента РФ, в рамках которого федеральными и региональными органами государственной власти России в 2020-2021 гг. ведется работа по подготовке и публикации в открытом доступе наборов данных (датасетов) с целью обучения на их основе алгоритмов ИИ (см. табл. 3). 
ИИ в городском управлении: данные

\begin{tabular}{|c|c|}
\hline Барьеры & Инструменты преодоления \\
\hline $\begin{array}{l}\text { 1. Отсутствует унифицирован- } \\
\text { ная методология обработки и } \\
\text { представления данных, имею- } \\
\text { щаяся информация не структу- } \\
\text { рирована. } \\
\text { 2. Низкий уровень доступности } \\
\text { городских данных. } \\
\text { 3. Недостаток данных для про- } \\
\text { гнозирования, разработки и } \\
\text { обучения алгоритмов ИИ. } \\
\text { 4. Низкое качество данных, } \\
\text { размещенных городом в откры- } \\
\text { том доступе / низкая востребо- } \\
\text { ванность этих данных рынком. } \\
\text { 5. Медленное обновление го- } \\
\text { родских наборов данных, раз- } \\
\text { мещенных в открытом доступе }\end{array}$ & $\begin{array}{l}\text { 1. Создание единой городской платфор- } \\
\text { мы деперсонализированных государ- } \\
\text { ственных и коммерческих наборов дан- } \\
\text { ных для разработчиков решений в сфере } \\
\text { ИИ, с обеспечением возможности до- } \\
\text { бавления новых данных. } \\
\text { 2. Системная работа по созданию набо- } \\
\text { ров данных, необходимых для разра- } \\
\text { ботки и применения ИИ-решений, по- } \\
\text { средством перевода в цифровой формат } \\
\text { соответствующей документации, име- } \\
\text { ющейся только в бумажном формате, } \\
\text { с их разметкой и размещением в откры- } \\
\text { том доступе. } \\
3 . \text { Разработка унифицированной мето- } \\
\text { дологии обработки, формата представ- } \\
\text { ления и обновления данных с их публи- } \\
\text { кацией в открытом доступе и популяри- } \\
\text { зацией. } \\
4 . \text { Разработка единого алгоритма досту- } \\
\text { па и владения различными категориями } \\
\text { данных }\end{array}$ \\
\hline
\end{tabular}

По состоянию на апрель 2021 г. ведомства доложили о подготовке 126 датасетов. Так, Минпромторг России выделил в качестве приоритетных базы данных для внедрения самообучаемой системы распознавания неструктурированного текста и интеллектуальной классификации, а также проактивного управления мерами государственной поддержки на основе интеллектуальных систем анализа данных. Значительное число ведомств (например, Минэкономразвития России) видят наиболее перспективной обработку с помощью ИИ входящей корреспонденции в системе электронного документооборота, а также аналитических данных (Сапрыкина 2021).

Не умаляя значимости этой работы и востребованности таких данных для внутренней цифровой трансформации ведомств, ре- 
спонденты отметили, что подобные датасеты зачастую не полезны бизнесу с точки зрения объемов и структуры содержащейся в них информации, так как они создаются государством и прежде всего в государственной логике. «Mbl скачали данные, размещенные на городском портале открытых данных, “поиграли” с ними, и стало ясно, что почти ничего из этого не может быть полезно для нашей компании. Периодически смотрим, какие новые данные появились на портале, но это по-прежнему не то, что нужно» (респондент 8 о датасетах, размещенных в открытом доступе).

Равным образом, отмечают респонденты, маловероятно, что публикация уже имеющихся датасетов, даже при условии их «обогащения», приведет к тому, что российский бизнес разработает принципиально новые ИИ-решения (хотя и будет содействовать развитию отрасли в целом). Альтернативным решением респонденты полагают введение инструмента субсидий для бизнеса на создание собственных датасетов, реализованных в бизнес-логике.

Инфраструктура. Для развития сферы ИИ принципиальное значение имеет состояние городской инфраструктуры, как физической, так и организационной, способствующей развитию инноваций (см. табл. 4). В России наблюдается нехватка инструментов поддержки идей и стартапов в сфере ИИ и необходимо решение целого комплекса соответствующих вопросов. Так, в 2018 г. в России прошло 500 хакатонов, тогда как в США - 1511. Менее $0,1 \%$ российских студентов вовлечены в работу университетских акселераторов, бизнес-инкубаторов, центров коллективного пользования и прототипирования - в то время как в США 54 \% основателей глобальных стартапов, которые оценены более чем в 1 млрд долларов, прошли через университетские акселераторы и другие инструменты развития бизнеса.

\section{Этика и доверие}

При развитии искусственного интеллекта в целом формировалось два противоборствующих течения. Одно - создание алгоритмов на основе правил (экспертные системы, программируемые логикой - кодировкой ответов экспертов). И другое - алгоритмы на принципах нейронных сетей (эксперты создавали нейронную имитацию, реконструкцию человеческого мозга, загружая в систему 
как можно больше цифр и предоставляя ей возможность находить решения и закономерности самостоятельно). Однако когда в 2012 г. нейронная сеть победила на международном конкурсе компьютерного зрения, второе течение окончательно взяло вверх.

Таблица 4

ИИ в городском управлении: инфраструктура

\begin{tabular}{|c|c|}
\hline Барьеры & Инструменты преодоления \\
\hline $\begin{array}{l}\text { 1. Недостаточная обеспечен- } \\
\text { ность отрасли суперкомпьюте- } \\
\text { рами, недостаточная обеспе- } \\
\text { ченность ЦОД коллективного / } \\
\text { индивидуального использова- } \\
\text { ния под выполнение задач ИИ. } \\
\text { 2. Высокая стоимость доступа } \\
\text { к вычислительным мощностям } \\
\text { для стартапов. } \\
\text { 3. Отсутствие крупных россий- } \\
\text { ских разработчиков и произво- } \\
\text { дителей специализированного } \\
\text { аппаратного обеспечения и вы- } \\
\text { сокий уровень зависимости от } \\
\text { импортных поставок оборудо- } \\
\text { вания и комплектующих. } \\
\text { 4. Малое количество профиль- } \\
\text { ных IТ-технопарков. } \\
\text { 5. Недостаточный уровень раз- } \\
\text { вития 5G-инфраструктуры. } \\
\text { 6. Недостаточное количество } \\
\text { инкубационных и акселера- } \\
\text { ционных программ по тема- } \\
\text { тике ИИ }\end{array}$ & $\begin{array}{l}\text { 1. Площадки локализации для компаний } \\
\text { (ИИ-кварталы). } \\
\text { 2. Обеспечение научных центров супер- } \\
\text { компьютерами высокой вычислитель- } \\
\text { ной мощности. } \\
\text { 3. Предоставление стартапам доступа } \\
\text { на выгодных условиях к суперкомпью- } \\
\text { терам, облачным сервисам и центрам } \\
\text { обработки данных. } \\
\text { 4. Создание производственных мощно- } \\
\text { стей по выпуску специализированного } \\
\text { аппаратного обеспечения. } \\
\text { 5. Создание технопарков по профилю ИИ. } \\
\text { 6. Содействие развертыванию сетей 5G } \\
\text { и широкого доступа населения к техно- } \\
\text { логии. } \\
\text { 7. Создание специализированных инку- } \\
\text { бационных и акселерационных про- } \\
\text { грамм в области ИИ. } \\
\text { 8. Проведение технологических конкур- } \\
\text { сов, хакатонов по решению конкретных } \\
\text { задач по разработке ИИ-решений }\end{array}$ \\
\hline
\end{tabular}

Этические проблемы, связанные с внедрением ИИ-решений, напрямую проистекают из механизмов функционирования ИИ-алгоритмов. Искусственный интеллект обучается на массивах данных, распознавая скрытые от человека закономерности. Специалист может облегчить их поиск с помощью разметки данных скажем, указать, что есть белое, а что - черное. В итоге алгоритм 
принимает решения, опираясь на собственные суждения о корреляциях, многие из которых неявны либо бессмысленны для человека.

По мнению академика РАН Константина Анохина, одного из руководителей проекта «Мозг и информация: от естественного интеллекта к искусственному», внедрение ИИ связано с нерешенной проблемой расшифровки когнитивного кода человеческого мозга. Как и мозг, ИИ состоит из миллионов нейронов (только искусственных) и также представляет собой «черный ящик»: «Системы ИИ становятся все сложнее, начинают вести себя все более непредсказуемо, выдавать дикие, на взгляд человека, ошибки, а мы не понимаем, в чем дело. Можно ли такому ИИ доверять решение ответственных задач?» (Медведев 2020).

Известный пример ложной корреляции - американская программа, которая распределяла больных в очереди по срочности оказания медицинской помощи, решила, что астматикам с пневмонией помощь нужна меньше, чем просто людям с пневмонией без астмы. Дело в том, что, по статистике, смертность астматиков намного ниже, а значит, можно понизить их приоритет в очереди. На самом же деле низкая смертность таких больных была связана именно с тем, что в медицинских учреждениях им оказывают помощь в первую очередь - как раз в связи с критическим положением (Маланов 2018).

Таким образом, внедрение сложных ИИ-решений в государственное управление потребует решения проблемы транспарентности и подотчетности, а также доверия к ИИ. Как отметили респонденты, вопрос доверия важен даже по отношению к наиболее простым и уже широко применяемым на практике решениям, таким как виртуальные ассистенты и голосовые помощники. Эту позицию подкрепляют результаты исследования П. Пурванто, К. Кусванди и Ф. Фатмах: ключевым барьером для граждан при использовании виртуальных ассистентов на базе ИИ (цифровых помощников) является низкий уровень двустороннего взаимодействия, то есть понимания пожеланий пользователя. Авторы подчеркивают: для того, чтобы пользователь доверял виртуальному помощнику, важно, чтобы он имел высокий уровень интерактивности. Последняя, в свою очередь, слагается из трех составляющих: управляемость - пользователь может контролировать содержание, продолжительность 
и последовательность операций; синхронность - виртуальный помощник обладает высокой скоростью реакции, отвечает на запросы четко и в режиме реального времени; двунаправленность - пользователь ощущает, что обменивается данными с виртуальным ассистентом как с равноправным участником коммуникации (Пурванто и др. 2020: 71). Поскольку доверие к виртуальному ассистенту напрямую определяет степень удовлетворенности его работой, анализ пользовательского опыта по указанным направлениям должен входить в число задач сотрудников ОИВов, отвечающих за внедрение технологий искусственного интеллекта в государственное управление.

Важным шагом в преодолении этических барьеров в сфере ИИ в России стало принятие ГОСТ Р 59276-2020 «Системы искусственного интеллекта. Способы обеспечения доверия», разработанного Техническим комитетом по стандартизации ТК 164 «Искусственный интеллект» на базе РВК. Документ вводит ряд понятий (центральных для решения комплекса этических проблем), таких как: 1) «доверенная система искусственного интеллекта»; «объяснимость» - «свойство системы искусственного интеллекта, заключающееся в возможности предоставления причин, приводящих к тому или иному решению системы, в виде, понятном человеку» (ГОСТ... 2021: 2); 2) «понятность» - «свойство системы искусственного интеллекта, заключающееся в возможности открытого, исчерпывающего, доступного, четкого и понятного представления информации» (Там же: 3); 3) «предсказуемость» - «свойство системы искусственного интеллекта, заключающееся в способности принимать решения ожидаемым (естественным, приемлемым) для человека способом», а также «представительный набор существенных характеристик» - «минимально необходимая и достаточная совокупность характеристик системы искусственного интеллекта, позволяющая потребителю, организациям, ответственным за регулирование вопросов создания и применения систем искусственного интеллекта, или любой другой заинтересованной стороне достоверно оценивать качество системы при решении конкретной прикладной задачи» (Там же).

В то же время, как показывает практика, реализация этих принципов для решения прикладных задач сопряжена со значительными 
сложностями. Поиск решения проблемы справедливости, ответственности и прозрачности алгоритмов ведет множество экспертных групп по всему миру. Здесь примечательны такие инициативы, как JHU GovEx's Ethics \& Algorithms Toolkit, AI Now's Algorithmic Impact Assessment, Canadian National Government's Algorithmic Impact Assessment. Эти практики призваны реализовать такие механизмы регулирования процесса внедрения ИИ-решений, как «право общественности на голос» и «способность реализовывать санкции».

Любопытным примером является работа независимых организаций по оценке алгоритмов, таких как Комитет по открытому правительству штата Нью-Йорк (Committee on Open Government), независимый от губернатора. Представители комитета вошли в созданный в Нью-Йорке Совет по автоматизированным системам (NYC Automated Decision Systems Task Force) - экспертную группу, в задачи которой входила выработка перспективных инструментов контроля над ИИ и взаимодействия в этом вопросе с властями города. Совет пришел к выводу, что для обеспечения подотчетности ИИ-алгоритмов перед внедрением соответствующего решения в городское управление горожане должны получить доступ к следующей информации:

- история разработки алгоритма;

- характеристики алгоритма;

- процесс обучения ADS-моделей;

- описание процесса принятия решения;

- записи тестов;

- публикация открытого кода либо хранение на эскроу-базе данных.

Экспертами было предложено ввести должность ИИ-омбудсмена, наделенного мэром города соответствующими полномочиями, в задачи которого входит оказание городу помощи гражданам в разрешении их обеспокоенности по поводу ИИ-решений, а также ряд других обязанностей.

Однако Совет констатировал, что власти города пока недостаточно открыты для диалога по этим вопросам. Кроме того, указанные требования к публикации данных об алгоритмах встретили критику разработчиков: по мнению ряда IT-компаний, публикация этой информации может привести к манипулированию алгоритмом 
в личных корыстных цุелях, нарушению прав интеллектуальной собственности и коммерческой тайны разработчиков. После публикации двух докладов деятельность Совета было решено приостановить в связи со сложившейся тупиковой ситуацией во взаимодействии с рынком и государством. Пример работы Совета показывает, что решение этических вопросов по внедрению ИИ - многогранная задача, урегулирование которой пока находится в начальной стадии.

\section{Заключение}

На современном этапе решения на базе технологий ИИ (прежде всего алгоритмы предиктивной аналитики, RPA-решения, в том числе по автоматизации документооборота, голосовые ассистенты и виртуальные помощники) уже активно применяются в управлении городом, позволяя оказывать более качественные и оперативные услуги и оптимизировать городской бюджет. Однако более масштабная цифровая ИИ-трансформация госсектора будет возможна лишь после преодоления целого ряда барьеров, центральными из которых являются барьеры нормативного и этического характера, а также аспекты, связанные с данными.

Внедрение ИИ не должно быть самочелью. Ключевая задача государства при внедрении новых технологий - обеспечить соблюдение этических норм, а также неприкосновенность личных данных граждан. В противном случае необдуманная цифровизация приведет к росту конфликтов в городском пространстве, появлению новых и усугублению существующих социальных расколов, резкому росту недоверия по отношению к власти.

Кроме того, в некоторых случаях целесообразнее не внедрять ИИ, а ограничиться более традиционными решениями. Например, как отмечают британские эксперты, для сбора информации из отсканированных паспортов можно использовать технологию цифрового распознавания документов, однако заполнение обычной электронной формы обеспечивает меньшую погрешность при обработке данных, менее затратно и намного проще в организации (A Guide... 2020: 10).

Внедряя инновационные технологии, городские власти должны отводить значительное время этапy тестирования решения - на циф- 
ровых двойниках, в рамках живых лабораторий, а также проводить системную работу с рынком и с населением, прежде чем внедрять решение на практике. Для этого необходимо обеспечить нормативно-правовую базу для использования ИИ (в том числе посредством такого инструмента, как экспериментальный правовой режим), формировать экспертные советы из числа представителей различных групп населения, вести активную просветительскую работу, направленную на разъяснение необходимости внедрения того или иного решения, а также на повышение общего уровня цифровой грамотности населения. Аналогичным образом, необходимо обеспечение ОИВов профессиональными кадрами для ИИ-трансформации и организация непрерывного обучения сотрудников.

\section{Литература}

ГОСТ Р 59276-2020. Системы искусственного интеллекта. Способы обеспечения доверия. Общие положения. 2021. М.: Стандартинформ. URL: https://allgosts.ru/35/240/gost_r_59276-2020 (дата обращения: 26.05 . 2021).

Косалс, Л. Я., Ячник, М. М. 2020. Рынок технологий искусственного интеллекта в России: социальные условия зарождения. Ст. 2. Разработчики, потребители и государство: взаимоотношения и перспективы. Общественные науки и современность 3: 5-17. URL: https://doi.org/10.31857/ S086904990010066-4.

Лотош, М. Р., Платонов, В. В., Ткалич, П. П. 2021. Барьеры на пути внедрения искусственного интеллекта в российских банках: размеры, причины, сроки и пути преодоления. Вопросы инновационной экономики 1(11): 315-332. URL: https://doi.org/10.18334/vinec.11.1.111529.

Маланов, А. 2018. 9 проблем машинного обучения. Kaspersky Daily 28 августа. URL: https://www.kaspersky.ru/blog/machine-learning-ten-challen ges/21193/ (дата обращения: 26.05.2021).

Медведев, Ю. 2020. Код мозга. Как увидеть рождение мысли. Российская газета - Столичный выпуск 237(8291) 20 октября. URL: https:// rg.ru/2020/10/20/akademik-anohin-sovremennyj-iskusstvennyj-intellekt-etochernyj-iashchik.html (дата обращения: 26.05.2021).

Пурванто, П., Кусванди, К., Фатмах, Ф. 2020. Интерактивные приложения с искусственным интеллектом: факторы доверия пользователей. Форсайm 2(14): 64-75. URL: https://doi.org/10.17323/2500-2597.2020.2.64.75. 
Сапрыкина, А. 2021. Министерства заготовили корм для ИИ. ComNews 2 апреля. URL: https://www.comnews.ru/content/213897/2021-04-02/ 2021-w13/ministerstva-zagotovili-korm-dlya-ii (дата обращения: 26.05.2021).

Эффекты от внедрения решений на базе искусственного интеллекта в российских компаниях. Исследование Ростелеком и Tadviser. 2020. М.: ПАО «Ростелеком». 13 с. URL: https:/www.tadviser.ru/images/8/89/ROS TELECOM_AI_0112.pdf (дата обращения: 26.05.2021).

2 Megatrends Dominate the Gartner Hype Cycle for Artificial Intelligence. 2020. Smarter With Gartner September 28. URL: https://www.gartner. com/smarterwithgartner/2-megatrends-dominate-the-gartner-hype-cycle-for-artiTficial-intelligence-2020/ (дата обращения: 26.05.2021).

A Guide to Using Artificial Intelligence in the Public Sector. 2020. UK Office for Artificial Intelligence January 27. URL: https:/www.gov.uk/govern ment/publications/a-guide-to-using-artificial-intelligence-in-the-public-sector (дата обращения: 26.05.2021).

Blumauer, A. 2020. How Semantic AI Is Shaking Up Business Models In The Banking Sector. Forbes March 12. URL: https:/www.forbes.com/sites/ forbestechcouncil/2020/03/12/how-semantic-ai-is-shaking-up-business-modelsin-the-banking-sector/?sh=98749a065393 (дата обращения: 26.05.2021).

Guidelines for AI Procurement. 2020. UK Office for Artificial Intelligence June 08. URL: https://www.gov.uk/government/publications/guidelinesfor-ai-procurement/guidelines-for-ai-procurement (дата обращения: 26.05.2021).

IDC Forecasts Improved Growth for Global AI Market in 2021. 2021. IDC 23.02. URL: https://www.idc.com/getdoc.jsp?containerId=prUS47482321 (дата обращения: 26.05.2021).

Making Cities Smarter. How Citizens' Collective Intelligence can Guide Better Decision Making. 2017. Deloitte Insights January 26. URL: https://www2. deloitte.com/insights/us/en/multimedia/podcasts/smarter-cities-collective-intelligence-decision-making.html (дата обращения: 26.05.2021).

Measuring Trends in Artificial Intelligence. 2021. The AI Index Report 2021. Standford University. URL: https://aiindex.stanford.edu/report/ (дата обращения: 26.05.2021). 